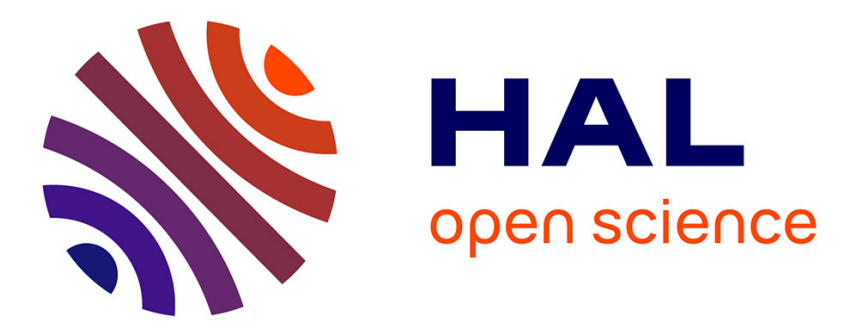

\title{
Rheological weakening of olivine + orthopyroxene aggregates due to phase mixing, Part2: Microstructural development
}

Miki Tasaka, Mark E. Zimmerman, David L. Kohlstedt, Holger Stünitz, Renée Heilbronner

\section{To cite this version:}

Miki Tasaka, Mark E. Zimmerman, David L. Kohlstedt, Holger Stünitz, Renée Heilbronner. Rheological weakening of olivine + orthopyroxene aggregates due to phase mixing, Part2: Microstructural development. Journal of Geophysical Research: Solid Earth, 2017, 122, pp.7597-7612. 10.1002/2017JB014311 . insu-01598292

\section{HAL Id: insu-01598292 \\ https://hal-insu.archives-ouvertes.fr/insu-01598292}

Submitted on 23 Oct 2017

HAL is a multi-disciplinary open access archive for the deposit and dissemination of scientific research documents, whether they are published or not. The documents may come from teaching and research institutions in France or abroad, or from public or private research centers.
L'archive ouverte pluridisciplinaire HAL, est destinée au dépôt et à la diffusion de documents scientifiques de niveau recherche, publiés ou non, émanant des établissements d'enseignement et de recherche français ou étrangers, des laboratoires publics ou privés. 


\section{Journal of Geophysical Research: Solid Earth}

\section{RESEARCH ARTICLE \\ 10.1002/2017JB014311 \\ This article is a companion to Tasak et al. (2017) https://doi.org/10.1002/ \\ Rheological Weakening of Olivine + Orthopyroxene Aggregates Due To Phase Mixing: Part 2. Microstructural Development} 2017JB014333.

Key Points:

- High strain torsion experiments on samples of iron-rich olivine + orthopyroxene were conducted

- A mechanism of phase mixing due to deformation is proposed

- It is Important for understanding strain weakening in shear zones

Supporting Information:

- Supporting Information S1

- Table S1

Correspondence to:

M. Tasaka,

tasaka@riko.shimane-u.ac.jp

Citation:

Tasaka, M., Zimmerman, M. E. Kohlstedt, D. L., Stünitz, H., \& Heilbronner, R. (2017). Rheological weakening of olivine + orthopyroxene aggregates due to phase mixing: Part 2 Microstructural development. Journal Geophysical Research: Solid Earth, 122. https://doi.org/10.1002/2017JB014311

Received 11 APR 2017 Accepted 24 AUG 2017 Accepted article online 8 SEP 2017

c2017. American Geophysical Union. All Rights Reserved.

\author{
Miki Tasaka ${ }^{1,2}$ (D), Mark E. Zimmerman ${ }^{1}$, David L. Kohlstedt ${ }^{1}$ iD, Holger Stünitz ${ }^{3,4}$, \\ and Renée Heilbronner ${ }^{5}$
}

${ }^{1}$ Department of Earth Science, University of Minnesota, Twin Cities, Minneapolis, MN, USA, ${ }^{2}$ Now at Department of Geoscience, Shimane University, Shimane, Japan, ${ }^{3}$ Department of Geology, University of Troms $\varnothing$, Tromsø, Norway, ${ }^{4}$ Institut des Sciences de la Terre d'Orléans, Université d'Orléans, Orléans, France, ${ }^{5}$ Geological Institute, Basel University, Basel, Switzerland

Abstract To understand the processes involved in phase mixing during deformation and the resulting changes in rheological behavior, we conducted torsion experiments on samples of iron-rich olivine plus orthopyroxene. The experiments were conducted at a temperature, $T$, of $1200^{\circ} \mathrm{C}$ and a confining pressure, $P$, of $300 \mathrm{MPa}$ using a gas-medium deformation apparatus. Samples composed of olivine plus $26 \%$ orthopyroxene were deformed to outer radius shear strains up to $\gamma \approx 26$. In samples deformed to lower strains of $\gamma \lesssim 4$, elongated olivine and pyroxene grains form a compositional layering. Already by this strain, mixtures of small equant grains of olivine and pyroxene begin to develop and continue to evolve with increasing strain. The ratios of olivine to pyroxene grain size in deformed samples follow the Zener relationship, indicating that pyroxene grains effectively pin the grain boundaries of olivine and inhibit grain growth. Due to the reduction in grain size, the dominant deformation mechanism changes as a function of strain. The microstructural development forming more thoroughly mixed, fine-grained olivine-pyroxene aggregates can be explained by the difference in diffusivity among $\mathrm{Me}$ (Fe or $\mathrm{Mg}$ ), O, and $\mathrm{Si}$, with transport of $\mathrm{MeO}$ significantly faster than that of $\mathrm{SiO}_{2}$. These mechanical and associated microstructural properties provide important constraints for understanding rheological weakening and strain localization in upper mantle rocks.

\section{Introduction}

Rheological weakening associated with localization of deformation strongly influences the strength and dynamics of the lithosphere (e.g., Bercovici et al., 2000; Bercovici \& Ricard, 2014; Tackley, 2000). Grain size reduction is considered the most likely weakening mechanism because mantle shear zones are often composed of very fine grained $(\sim 1$ to $\sim 10 \mu \mathrm{m}$ ) mylonites and ultramylonites (Handy \& Stünitz, 2002; Warren \& Hirth, 2006). In naturally deformed peridotites, fine-grained regions composed of two or more thoroughly mixed phases provide a pathway for strain localization (Czertowicz et al., 2016; Linckens et al., 2011, 2015; Tasaka et al., 2014; Warren \& Hirth, 2006). In such fine-grained, more thoroughly mixed, regions, the secondary phases pin the grain boundaries of olivine and minimize grain growth, allowing the rock to deform by a grain size sensitive creep mechanism, such as dislocation-accommodated grain boundary sliding (disGBS) or diffusion creep (diffusion-accommodated grain boundary sliding). As a result, deformation can localize in these fine-grained regions under grain size sensitive creep. Therefore, the formation of more thoroughly mixed, fine-grained rocks is important in the development of strain weakening and strain localization.

Based on observations of naturally deformed rocks, previous studies suggested various mechanisms accompanying recrystallization for the formation of a more thoroughly mixed, fine-grained microstructure. These mechanisms include chemical reactions with melt and/or fluids, metamorphic reactions, brittle deformation or comminution, mechanical mixing (entrainment) of adjacent materials, and creep cavitation (Czertowicz et al., 2016; Jin et al., 1998; Kelemen \& Dick, 1995; Newman et al., 1999; Precigout et al., 2017; Warren \& Hirth, 2006). Experimental studies are needed to make further progress in this area because the mechanisms for forming thoroughly mixed, fine-grained microstructures are difficult to capture from observations of naturally deformed rocks due to their complicated deformation history and subsequent alteration.

Previous experimental studies also argue that dynamic recrystallization may occur as a recovery process during dislocation creep and/or disGBS, producing a more thoroughly mixed microstructure (Farla et al., 
2013; Linckens et al., 2014). Unfortunately, the complex, transient microstructures produced in these experiments and the low resolution of the mechanical data left the role of phase mixing in the development of strain weakening unclear. Consequently, the mechanisms by which more thoroughly mixed microstructures produce rheological weakening are not well understood, and very few experimental data exist that demonstrate this effect.

To investigate the processes that lead to rheological weakening in two-phase rocks, we conducted torsion experiments on aggregates of iron-rich olivine plus orthopyroxene in a high-resolution, gas-medium apparatus. In this paper, we focus on the microstructural development. In a companion paper (Tasaka et al., 2017), we examined the mechanical behavior. The evolution of mechanical and microstructural properties provides a framework for understanding rheological weakening and strain localization under upper mantle conditions.

\section{Background}

\subsection{Grain Size Piezometer}

With sufficient strain in a single-phase sample deforming by a dislocation-accommodated creep mechanism, the grain size will evolve to a steady-state determined by the level of the flow stress. The resulting piezometric relationship is written as

$$
d_{\mathrm{ss}}=A_{1} / \sigma_{\mathrm{ss}}{ }^{q}
$$

where $A_{1}$ and $q$ are material-dependent parameters, $d_{\mathrm{ss}}$ is the steady-state grain size, and $\sigma_{\mathrm{ss}}$ is the steadystate stress (Hirth \& Kohlstedt, 2015; Twiss, 1977).

\subsection{Zener Relationship}

When polyphase aggregates are statically annealed and/or deformed by a diffusion creep mechanism, the ratio of the grain size of the primary phase to the grain size of the secondary phase, $d_{1} / d_{11}$, evolves to a steady-state determined by the Zener relationship (Smith, 1948). This phenomenon, often referred to as Zener pinning, occurs because the secondary phase effectively pins the grain boundaries of the primary phase. As a result, the grain size of the primary phase is kept smaller than it would be in a single-phase material experiencing the same thermomechanical conditions. The grain size ratio is predicted to vary inversely with the volume fraction of the secondary phase, $f_{\| 1}$, as

$$
d_{1} / d_{\|}=\beta /\left(f_{\|}\right)^{z},
$$

where $\beta$ and $z$ are the Zener parameters. Various grain growth models and experiments yield values of $\beta$ and $z$ in the range of $0.7 \leq \beta \leq 4.5$ and $0.3 \leq z \leq 1.0$ (Evans et al., 2001; Hiraga et al., 2010; Manohar et al., 1998; Smith, 1948; Tasaka \& Hiraga, 2013).

\section{Experimental Procedure}

\subsection{Sample Preparation and Deformation Experiments}

We used iron-rich olivine and orthopyroxene (pyroxene), $\left(\mathrm{Mg}_{0.5} \mathrm{Fe}_{0.5}\right)_{2} \mathrm{SiO}_{4}$, and $\left(\mathrm{Mg}_{1.1} \mathrm{Fe}_{0.9}\right) \mathrm{Si}_{2} \mathrm{O}_{6}\left(\mathrm{Fo}_{50}\right.$ and $\left.E n_{55}\right)$, with a pyroxene volume fraction, $f_{p x}$ of 0.26 , for the high-strain torsion experiments because the relatively low strength of iron-rich olivine and enstatite allowed us to explore a wider range of strain rate and to reach higher strains than possible with samples prepared from Fo 90 plus En fo $_{90}$ (e.g., Hansen et al., 2012; Tasaka et al., 2016). For application to Earth's upper mantle, the mechanical and microstructural behavior of $\mathrm{Fo}_{50} \mathrm{Can}$ be scaled to that of $\mathrm{Fo}_{90}$ since the effect of iron on rheological behavior has previously been determined (Tasaka et al., 2015; Zhao et al., 2009).

Samples were deformed in torsion at a constant twist rate. The torsion experiments were conducted at $P=300 \mathrm{MPa}, T=1200^{\circ} \mathrm{C}$, and equivalent controlling outer-radius strain rates of $3.2 \times 10^{-5}$ to $4.6 \times 10^{-4} \mathrm{~s}^{-1}$. The resulting equivalent outer-radius stresses from the last portion of deformation experiments were 72 to $118 \mathrm{MPa}$. The method used to prepare olivine and pyroxene aggregates and details of the sample assembly are described in our companion paper. The chemical composition of the samples was determined using a JEOL-JXA-8900 electron probe microanalyzer (EPMA). The chemical compositions of olivine and pyroxene are summarized in Table S1 of the supporting information. 
Table 1

Summary of the Experiments

\begin{tabular}{|c|c|c|c|c|c|c|c|c|c|c|}
\hline \multirow[b]{2}{*}{ Experiment \# } & \multicolumn{2}{|c|}{ Undeformed sample } & \multicolumn{8}{|c|}{ Deformed sample } \\
\hline & PT-983 & 991 & PT-994 & 996 & 984 & 998 & 1024 & 990 & 1006 & 1012 \\
\hline Flow Stress (MPa) & - & - & 108 & 82 & 96 & 118 & 99 & 93 & 76 & 72 \\
\hline Strain Rate $\left(10^{-4} s^{-1}\right)$ & - & - & 2.47 & 0.32 & 1.90 & 4.64 & 2.30 & 1.65 & 2.13 & 4.62 \\
\hline Shear Strain & - & - & 1.9 & 2.0 & 4.2 & 4.2 & 10.9 & 17.3 & 26.2 & 25.3 \\
\hline$d_{\mathrm{EA} \_\mathrm{ol}}(\mu \mathrm{m})$ & 6.5 & 5.8 & 2.9 & 4.5 & 2.9 & 1.7 & 1.4 & 2.3 & 2.3 & 1.9 \\
\hline$d_{\text {EA_px }}(\mu \mathrm{m})$ & 5.2 & 4.1 & 1.7 & 2.4 & 1.9 & 1.1 & 1.1 & 1.3 & 1.3 & 1.0 \\
\hline$d_{\mathrm{ol}}(\mu \mathrm{m})$ & 8.3 & 7.4 & 3.7 & 5.7 & 3.6 & 2.2 & 1.8 & 2.9 & 2.8 & 2.4 \\
\hline$d_{\mathrm{px}}(\mu \mathrm{m})$ & 6.6 & 5.3 & 2.3 & 3.1 & 2.4 & 1.4 & 1.4 & 1.7 & 1.6 & 1.3 \\
\hline$\mu_{h \_ \text {ol }}(\mu \mathrm{m})$ & 7.8 & 4.6 & 3.2 & 3.0 & 3.2 & 1.3 & 1.7 & 1.7 & 2.5 & 1.4 \\
\hline$\mu_{h \_\mathrm{px}}(\mu \mathrm{m})$ & 6.5 & 2.7 & 2.7 & 2.0 & 2.8 & 1.0 & 1.6 & 1.3 & 1.8 & 1.0 \\
\hline$\mu_{v \_\mathrm{ol}}(\mu \mathrm{m})$ & 16.1 & 14.0 & 8.5 & 12.8 & 9.3 & 4.5 & 4.1 & 5.2 & 4.6 & 3.8 \\
\hline$\mu_{v \_\mathrm{px}}(\mu \mathrm{m})$ & 14.5 & 12.6 & 4.4 & 5.6 & 4.9 & 2.6 & 2.2 & 2.1 & 2.3 & 1.6 \\
\hline$N_{\mathrm{Ol}}$ & 2643 & 881 & 1450 & 364 & 1319 & 290 & 2008 & 343 & 1300 & 527 \\
\hline$N_{\mathrm{px}}$ & 1337 & 488 & 1504 & 566 & 2070 & 570 & 2175 & 640 & 1552 & 743 \\
\hline$f_{\mathrm{px}}$ & 0.27 & 0.25 & 0.25 & 0.28 & 0.35 & 0.41 & 0.33 & 0.33 & 0.25 & 0.25 \\
\hline
\end{tabular}

Note. $N_{\mathrm{ol}}$ and $N_{\mathrm{px}}$ : The number of analyzed olivine and pyroxene grain.

\subsection{Microstructural Analysis}

Portions of both undeformed and deformed samples were polished to analyze the microstructures. For the deformed samples, sections tangent to the external boundary of the sample cylinder (tangential sections) were prepared. These sections are approximately parallel to the shear direction and perpendicular to the shear plane. The specimens were polished using a diamond lapping film with grit sizes from 30 to $0.5 \mu \mathrm{m}$ followed by colloidal silica of a grain size of $40 \mathrm{~nm}$.

The polished surfaces were thermally etched at $1150^{\circ} \mathrm{C}$ for $0.5 \mathrm{~h}$ in a $1.5: 1$ mixture of $\mathrm{CO}: \mathrm{CO}_{2}$ to expose grain and phase boundaries. Minimal microstructural changes occurred during this thermal etching step, as confirmed by comparing the grain sizes determined from electron backscattered diffraction (EBSD) analyses before etching and after etching.

\subsubsection{Grain Size Measurement}

After etching, sections were first examined with a scanning electron microscope (SEM) equipped with a field emission gun (JEOL 6500F). Outlines of grains for each mineral were traced on secondary electron images (SEIs) to obtain the area of each grain. The sizes of olivine and pyroxene grains were calculated as the diameters of equivalent-area circles, $d_{\mathrm{EA}}=2(S / \pi)^{0.5}$, where $S=$ cross sectional area of the grain. The arithmetic means, $d_{\mathrm{EA} \_ \text {ol }}$ and $d_{\mathrm{EA} \_\mathrm{px}}$, were determined as the olivine and pyroxene equivalent area diameter. The grain sizes, $d_{\mathrm{ol}}$ and $d_{\mathrm{px}}$, include a scaling factor of $4 / \pi$, assuming a spherical particle shape (Underwood, 1970, p. 91). The pyroxene volume fraction was calculated from the area fraction of the pyroxene phase determined from image analysis. The measured volume fraction of pyroxene in the undeformed samples was $f_{\mathrm{px}}=0.26 \pm 0.01$ and was $0.24 \leq f_{\mathrm{px}} \leq 0.41$ in the deformed samples depending on the analyzed area (Table 1).

To determine the grain size distribution in more detail, histograms of the number-weighted and volumeweighted size distributions of 3-D grains, $h(D)$ and $v(D)$, were estimated from the size distributions $h\left(d_{\mathrm{EA}}\right)$ of 2-D sections using STRIPSTAR (Heilbronner \& Barrett, 2014). The arithmetic means, $\mu_{v}$ and $\mu_{h}$, of $v(D)$ and $h(D)$ were then calculated as $\mu_{v}=\Sigma\left(v_{\mathrm{i}}\left(D_{\mathrm{i}}\right) \cdot D_{\mathrm{i}}\right)$ and $\mu_{h}=\Sigma\left(h_{\mathrm{i}}(\mathrm{D}) \cdot D_{\mathrm{i}}\right)$, where $D=$ diameter of the volumeequivalent sphere. The values are summarized in Table 1. It should be noted that comparing grain sizes measured by different methods likely introduces a systematic bias. Because Hansen et al. (2012) used the line-intercept method to estimate grain size while we used STRIPSTAR to calculate the grain size, we reanalyzed the grain sizes in their study using SRIPSTAR in order to compare our results with theirs.

\subsubsection{Boundary Length Measurement}

In olivine (ol) + pyroxene (px) samples, three types of boundaries are present, ol-ol and px-px grain boundaries and ol-px phase boundaries. On phase and grain boundary maps, the total lengths of all ol-ol, px-px, and ol-px boundaries were measured. From the data, fractional length of the ol-px phase boundaries and 
the volume fraction of pyroxene were calculated. An average of 600 boundary segments of all types was measured for each map. Boundary segments connect two-, three-, or four-grain junctions.

\subsubsection{Analysis of Crystallographic Orientation}

The texture of the olivine and pyroxene grains was analyzed to study the development of crystallographic preferred orientation (CPO). Highly polished sections were coated with a $50 \AA$ thick carbon film and analyzed using a SEM-EBSD system (JEOL 6500F) with the HKL Channel5 software package. EBSD patterns were obtained using a standard tilt angle of $70^{\circ}$, an acceleration voltage of $20 \mathrm{kV}$, and a probe current of $20 \mathrm{nA}$. Typically, an area of $400 \times 500 \mu \mathrm{m}$ was analyzed for each sample using a grid spacing of $1 \mu \mathrm{m}$ for undeformed samples and $0.7 \mu \mathrm{m}$ for deformed samples depending on the sample grain size. To avoid analytical errors, grains composed of less than 4 pixels were not included. Olivine grains were indexed based on the forsterite structure; in this case, the fraction of the original EBSD map for which diffraction patterns could be indexed was $\sim 50 \%$. Pyroxene grains could not be indexed, possibly because the available pyroxene index file is based on iron-free pyroxene.

The microstructures were further examined using a field emission SEM (Zeiss Merlin compact field emission (FE)-SEM) with the AZtecHKL software package. EBSD analyses were performed using the standard tilt angle of $70^{\circ}$, an acceleration voltage of $15 \mathrm{kV}$, and a probe current of $7.8 \mathrm{nA}$. Crystallographic orientation maps were constructed with a grid spacing of $60 \mathrm{~nm}$. Here both olivine and pyroxene grains could be indexed using the Mg-end member structures. For all samples, the indexing rate was $>70 \%$, increasing to $>90 \%$ after noise reduction.

\section{Results}

\subsection{Microstructural Results}

Low-magnification SEI micrographs from tangential sections of two undeformed and eight samples deformed in torsion are presented in Figure 1. In samples deformed to relatively low strains $(\gamma \leq 4.2)$, elongated aggregates of dynamically recrystallized olivine and pyroxene grains are arranged in layers oriented at low angles relative to the shear plane. In samples deformed to high strains $(\gamma \geq 17.3)$, more thoroughly mixed, smaller, equant grains of olivine and pyroxene dominate the microstructure. The inclination angle relative to the shear plane of the compositional layering defined by the olivine or pyroxene aggregates (i.e., foliation) decreases with increasing strain, as observed in Figure 1. For each sample, the orientation of the long axis of the strain ellipse calculated from the relation $\gamma=2 / \tan (2 \theta)$, where $\theta$ is the angle of strain ellipse relative to the shear plane, is also included in Figure 1 for comparison. The inclination angles determined from the orientation of the grain aggregates are consistent with the angle calculated from the strain ellipse within a factor of 1.5. Grain size decreases with increasing shear strain; that is, the average 3-D sizes of both olivine and pyroxene grains, $\mu_{v_{-} \mathrm{ol}}$ and $\mu_{v_{-} \mathrm{px}}$, decrease from 13 to $16 \mu \mathrm{m}$ in the undeformed samples to $\mu_{v_{-} \text {ol }} \leq 5 \mu \mathrm{m}$ and $\mu_{v \_ \text {px }} \leq 2 \mu \mathrm{m}$ in samples deformed to high strains (Table 1 ).

The high-magnification SEI micrographs in Figure 2 of a sample deformed to relatively low strain $(\gamma \leq 4.2)$ show detailed features of the alternating olivine-rich and pyroxene-rich layers. Notably, in Figure 2b, small, approximately equant pyroxene grains $\left(d_{\mathrm{px}} \approx 1 \mu \mathrm{m}\right)$ form layer-parallel trails along grain boundaries of elongated olivine grains (long axis $\approx 10 \mu \mathrm{m}$ ). Likewise, in Figure $2 \mathrm{c}$, small olivine grains $\left(d_{\mathrm{ol}} \approx 1 \mu \mathrm{m}\right)$ form layer-normal trails along grain boundaries of larger pyroxene grains ( $\left.d_{\mathrm{px}} \approx 4 \mu \mathrm{m}\right)$.

\subsection{Grain Sizes and Grain Shape of Olivine and Pyroxene}

The grain size distributions presented in Figure 3 for the undeformed sample and for samples deformed at a strain rate of $\sim 2 \times 10^{-4} \mathrm{~s}^{-1}$ demonstrate that with increasing strain the distributions shift to smaller grain sizes than observed for an undeformed sample. This result is particularly obvious for the $v(D)$ distributions (green for olivine and blue for pyroxene in Figure 3). In the undeformed sample, the $v(D)$ distributions are approximately symmetric, and, therefore, the modes are approximately equal to the means; that is, $\mu_{v_{-}}$ol and $\mu_{v-\mathrm{px}}$ are 13 to $16 \mu \mathrm{m}$ (see also Table 1 ). In samples deformed to low strain $(\gamma \leq 4.2$ ), the mean grain size of olivine decreased by a factor of $2\left(\mu_{v_{-} \text {ol }} \approx 9 \mu \mathrm{m}\right)$ and that of pyroxene by a factor of 3 to 4 ( $\mu_{v_{-}}$px $\left.\approx 4 \mu \mathrm{m}\right)$. In samples deformed to high strains $(\gamma \geq 25)$, a further decrease by a factor of 2 yields $\mu_{v_{-} \text {ol }} \approx 4 \mu \mathrm{m}$ and $\mu_{v_{-} \mathrm{px}} \approx 2 \mu \mathrm{m}$. 


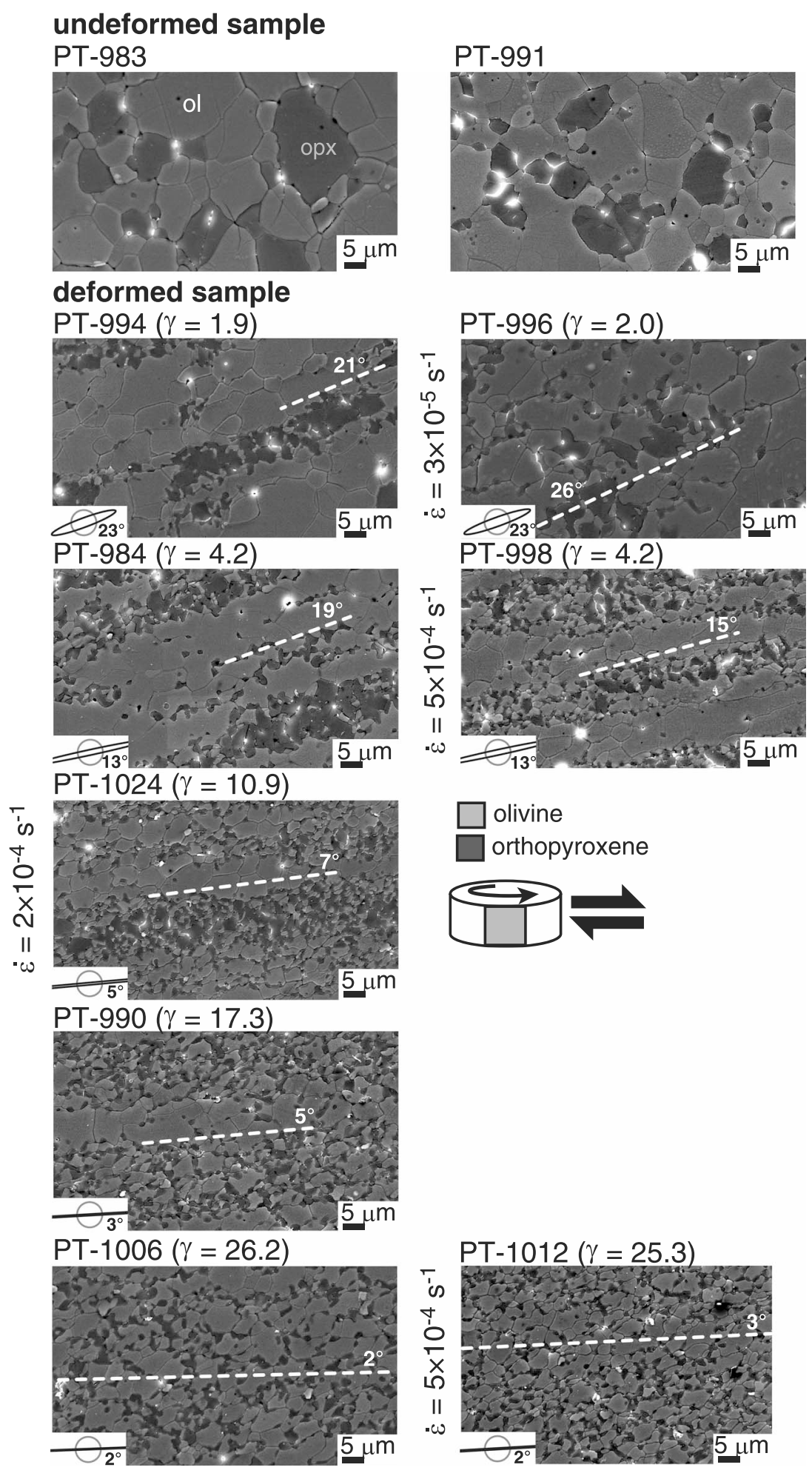

Figure 1. Secondary electron images of tangential sections of both undeformed and deformed samples. All samples were deformed top to the right. The light gray mineral is olivine, and the dark gray phase is pyroxene. White dotted lines indicate the foliation due to the compositional layering of olivine and/or pyroxene aggregates. The inclination angle from the grain aggregate is added next to the line. The strain ellipse calculated from the measured shear strain is illustrated in the lower left of each image along with the angle of its long axis. 
(a)

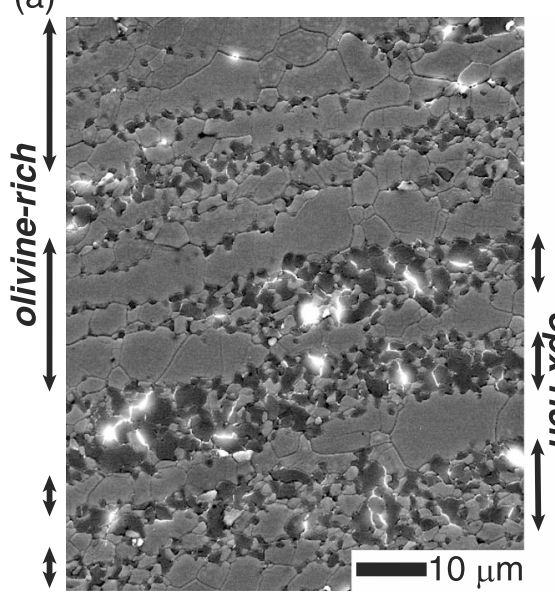

(b) olivine-rich

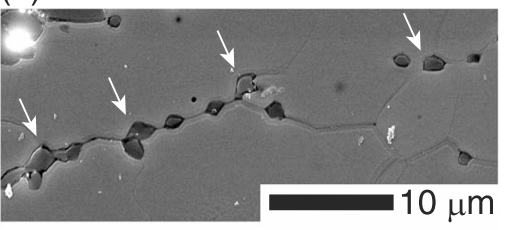

(c) opx-rich

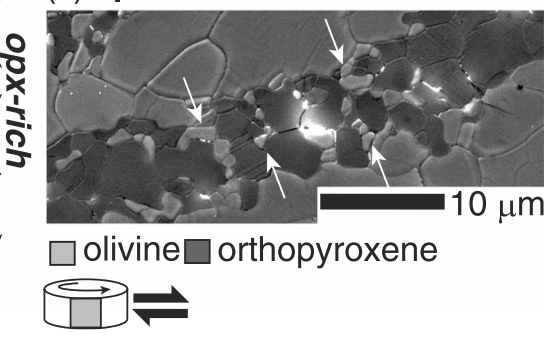

Figure 2. Secondary electron images from tangential sections of samples deformed to low shear strain. All samples were deformed top to the right. (a) Lowmagnification image of sample PT-998 deformed to $\gamma=4$.2. Black arrows to the left of the image indicate olivine-rich layers, whereas those to the right of the image indicate pyroxene-rich layers. (b) Higher magnification image of olivine-rich layer in sample PT-984 deformed to $\gamma=4.2$. White arrows mark small pyroxene grains. (c) Higher magnification image of pyroxene-rich layer in sample PT-994 deformed to $\gamma=1.9$. White arrows point out small olivine grains.

The rose diagrams of grain shape preferred orientation (SPO) of olivine and pyroxene grains in Figure 4 demonstrate that the undeformed samples are composed of approximately equant olivine and pyroxene grains. In contrast, both olivine and pyroxene grains are elongated and tilted $\sim 30^{\circ}$ relative to the shear direction in deformed samples. The angle of the maximum in the SPO is $\sim 30^{\circ}$, independent of shear strain. Thus, the angle between the SPO maximum and the strain ellipse increases with increasing strain from $\sim 10^{\circ}$ at $\gamma=4.2$ to $\sim 30^{\circ}$ for $\gamma=26.2$. The strength of the SPO for olivine is much greater than that for pyroxene. The olivine [100] CPO maxima are added for comparison.

To compare our grain sizes to published data, the arithmetic means determined from histograms of the volume-weighted size distribution of grain sizes as a function of stress are plotted in Figure 5. In samples deformed to lower strains $(1.9 \leq \gamma \leq 4.2)$, the size of the olivine and pyroxene grains decreases linearly with increasing stress. In contrast, in samples deformed to higher strain $(\gamma \gtrsim 11)$, the grain size is approximately constant regardless of the applied stress with $3.8 \leq \mu_{v_{-} \mathrm{ol}} \leq 5.2 \mu \mathrm{m}$ and $1.6 \leq \mu_{v_{-} \mathrm{px}} \leq 2.3 \mu \mathrm{m}$. The piezometric relationship (equation (R1)) determined from steady-state microstructures in sheared $\mathrm{Fo}_{50}$ aggregates with $f_{\mathrm{px}}=0$ (Hansen et al., 2012) is included in Figure 5 for comparison.

The average sizes of olivine grains versus the average sizes of pyroxene grains in undeformed and deformed samples are plotted in Figure 6. The grain sizes of the deformed samples fit a straight line, whereas the grain sizes of the undeformed samples do not fit this trend. To examine the difference, the Zener relationship obtained by Hiraga et al. (2010) for the forsterite-enstatite system with $z=0.59, \beta=0.74$, and $f_{\mathrm{px}}=0.26$ is added. As demonstrated in the plot, $d_{\mathrm{ol}}$ and $d_{\mathrm{px}}$ determined from deformed samples follow the Zener line within a factor of 1.1. In contrast, in undeformed samples, the estimated values for $d_{\mathrm{ol}}$ and $d_{\mathrm{px}}$ differ from the observed values by a factor of 1.3. The difference may indicate incomplete mixing of the two-phase powders.

\subsection{Grain Boundaries and Phase Boundaries}

The relative frequency of phase boundaries, $f_{\mathrm{PB}}$, compared to grain boundaries provides a good indicator of the distribution of two-phase aggregates as random, clustered, or ordered (anticlustered) (section 18 in Heilbronner \& Barrett, 2014). The frequencies of phase boundaries, $f_{\mathrm{PB} \_o b s,}$ in the undeformed and deformed samples are plotted in Figure 7a versus the pyroxene volume fraction derived from the area fraction at the

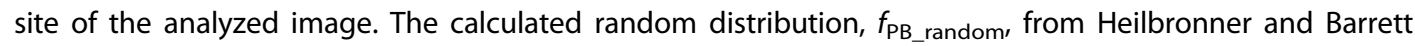
(2014) is included in Figure 7a for comparison with our data. Here the random distribution function was calculated assuming nearly equant grains with no SPO. All measurements of $f_{\mathrm{PB} \_ \text {obs }}$ plot above the curve for a random spatial distribution. 

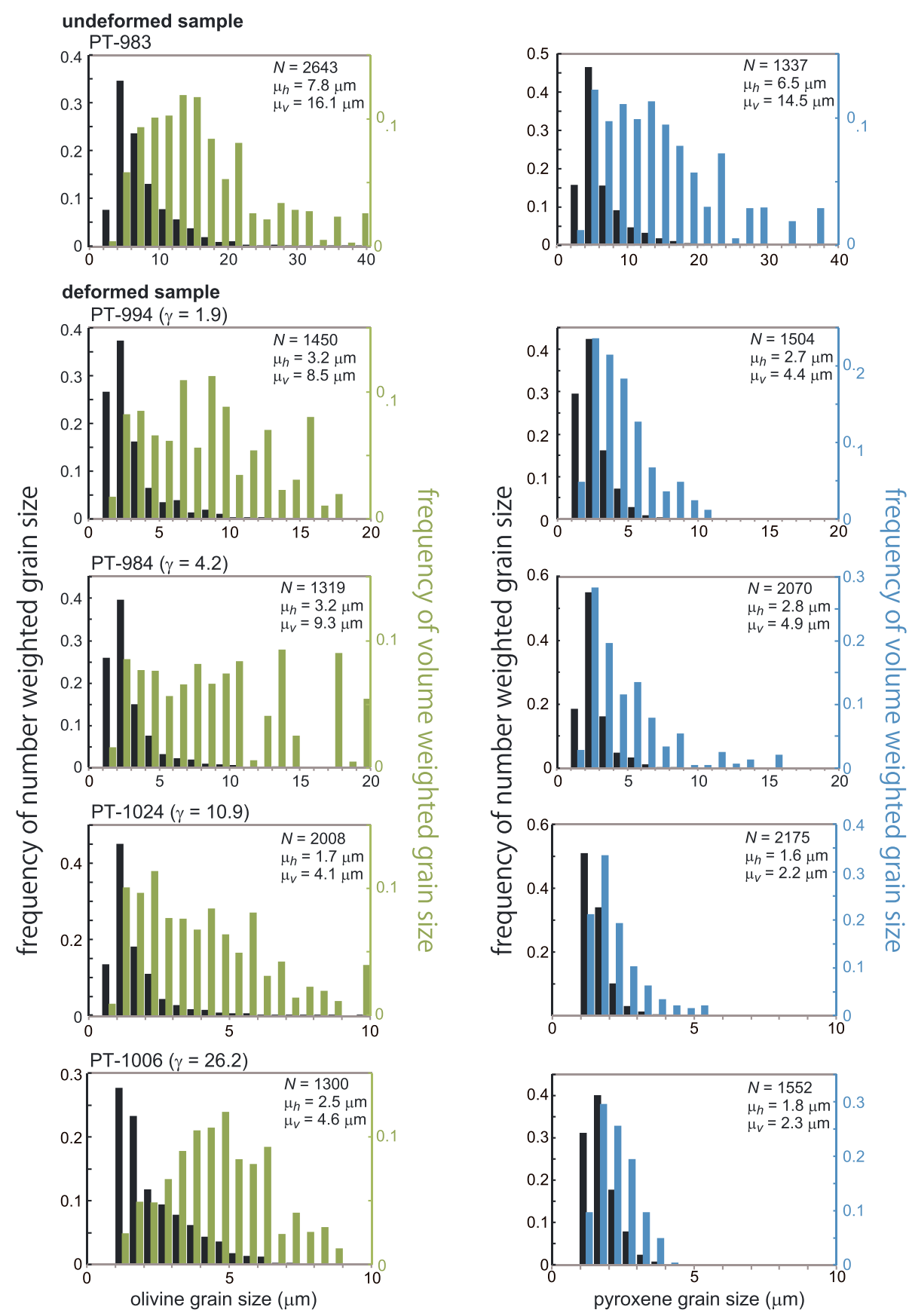

pyroxene grain size $(\mu \mathrm{m})$

Figure 3. Number-weighted and volume-weighted histograms, $h(D)$ and $v(D)$, of 3-D grain sizes for the undeformed sample and for samples deformed at a strain rate of $\sim 2 \times 10^{-4} \mathrm{~s}^{-1}$ with arithmetic means, $\mu_{h}$ and $\mu_{v}$, for olivine and pyroxene indicated. Black histograms: Number-weighted grain-size distributions for (left column) olivine and (right column) pyroxene. Green and blue histograms: Volume-weighted grain size distributions for olivine and pyroxene, respectively. $N$ is the number of grains analyzed.

To analyze the spatial distribution of olivine and pyroxene grains as a function of strain, the difference between $f_{\mathrm{PB} \_ \text {obs }}$ and $f_{\mathrm{PB} \_ \text {random }}$ versus shear strain is plotted in Figure $7 \mathrm{~b}$. The difference between $f_{\mathrm{PB} \_ \text {obs }}$ and $f_{\mathrm{PB} \_ \text {random }}$ increases with increasing strain. The differences are $\left(f_{\mathrm{PB} \_o b s}-f_{\mathrm{PB} \_ \text {random }}\right)=0.02$ and 0.10 for the two undeformed samples, whereas $0.08 \leq\left(f_{\mathrm{PB}_{-} \text {obs }}-f_{\mathrm{PB}_{-} \text {random }}\right) \leq 0.19$ for the samples deformed to $\gamma \leq 4.2$ and $0.15 \leq\left(f_{\mathrm{PB} \_ \text {obs }}-f_{\mathrm{PB} \_ \text {random }}\right) \leq 0.29$ for samples deformed to $\gamma \geq 11$. These positive differences indicate that the distribution of phases is more ordered than random. 


\section{undeformed sample}
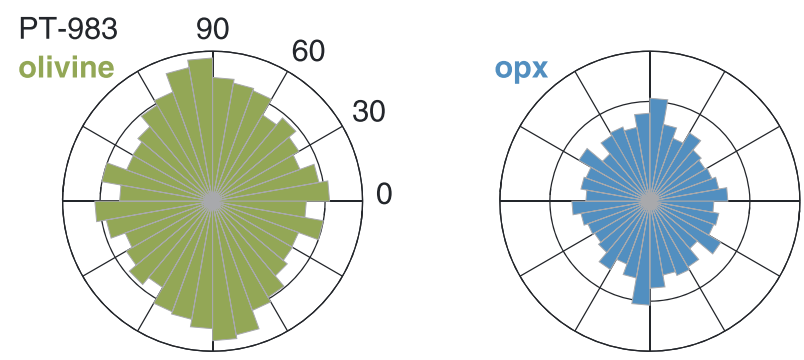

deformed sample
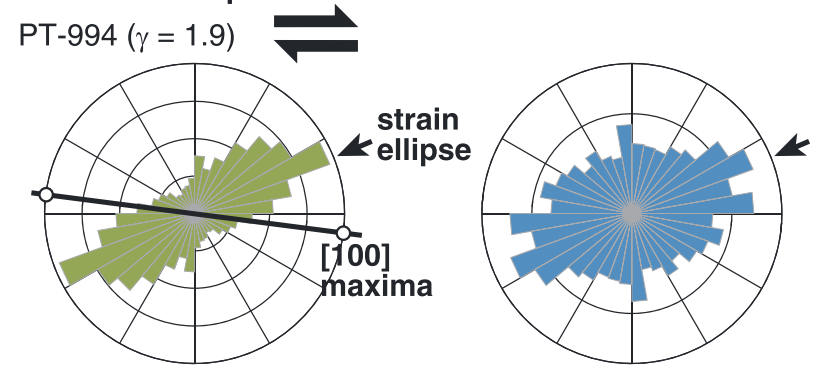

PT-984 $(\gamma=4.2)$
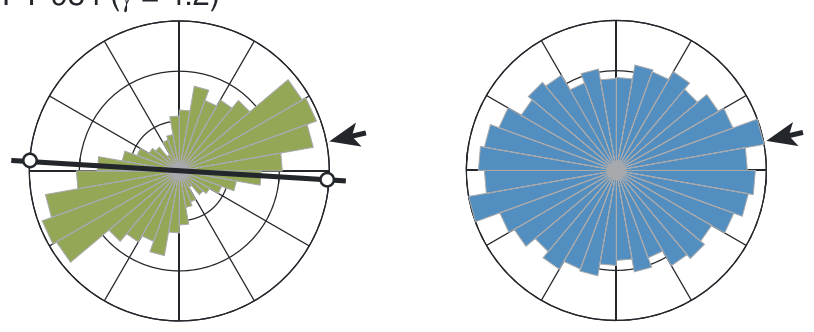

PT-1024 $(\gamma=10.9)$
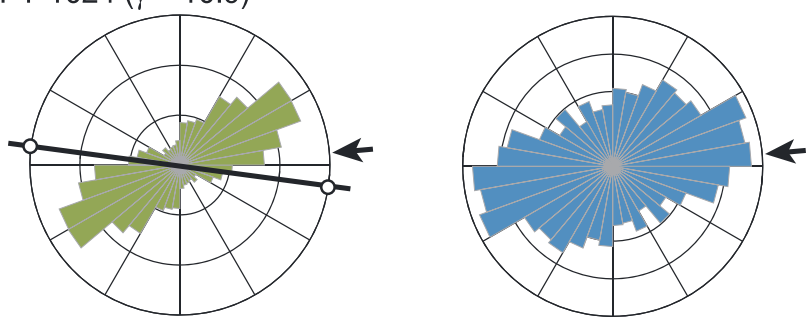

PT-1006 $(\gamma=26.2)$
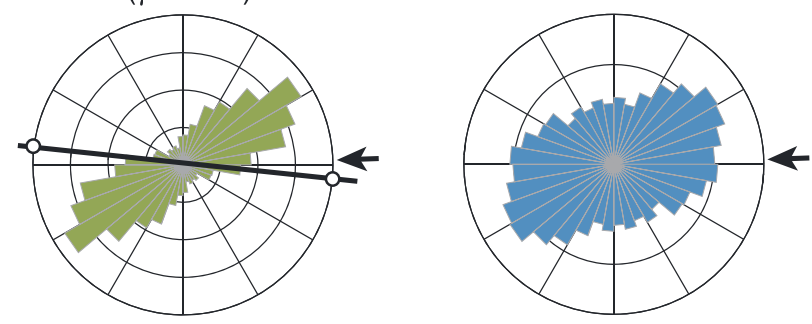

Figure 4. Rose diagrams illustrating the SPOs of olivine and pyroxene grains for the undeformed sample and for samples deformed at a strain rate of $\sim 2 \times 10^{-4} \mathrm{~s}^{-1}$. The thick back line with open circles for deformed samples indicates the olivine [100] CPO maxima from Figure 8. The angle between the $\mathrm{SPO}$ and $\mathrm{CPO}$ lines in the range 30 to $40^{\circ}$ regardless of shear strain. The contour lines for frequency in the rose diagram are drawn every 50 grains. The angle of the strain ellipse long axis calculated from the measured shear strain is illustrated by a black arrow. The same texture analysis data were used to determine grain size distribution in Figure 3.

\subsection{Crystallographic Fabrics}

The evolution of the texture of olivine is illustrated in Figure 8. The CPO of the undeformed samples is weak with an approximately uniform distribution ( $J=1.35$ to 1.39 ), whereas the CPO of most of the deformed samples is pronounced $(J>4)$. In samples deformed to low strains, $\gamma \approx 2.0$, the [100] axes are approximately parallel to the shear direction ( $X$, see sample coordinates in Figure 8 ) with girdles for the [010] and [001] axes. In samples deformed to a somewhat higher strain of $\gamma=4.2$, the [010] axes begin to form a maximum close to the $Z$ direction, approximately normal to the shear plane. In samples deformed to much higher strains, $\gamma \gtrsim 17$, the [100] axes are slightly inclined with respect to the $X$ direction in the sense of shear, while the [010] axes are slightly inclined to the $Z$ direction. The plot of $J$ index versus strain in Figure $S 1$ demonstrates that fabric strength increases with increasing strain for $\gamma<4.2$ and then gradually decreases with further increases in strain for $4.2 \leq \gamma \leq 26.2$. The EBSD maps in Figure S2 identify olivine grain boundaries and subgrain boundaries. Numerous, approximately vertical subgrain boundaries are evident in elongated grains in the sample deformed to lower strain $(\gamma=4.2)$, whereas very few subgrain boundaries are observed in the sample deformed to higher strain $(\gamma=25.3)$. Furthermore, the detailed textural analysis of sample PT-1006 (Figure S3) demonstrates that the CPO pattern does not change with grain size. In addition, the $J$ index is $\sim 1.7$ essentially independent of grain size for $d_{\text {ol }}<5 \mu \mathrm{m}$ but is somewhat larger at $\sim 2.7$ for $d_{\mathrm{ol}} \geq 5 \mu \mathrm{m}$. $M$ index values follow a trend similar to that of the $J$ index values.

To determine the difference between the CPO in olivine-rich layers and that in the pyroxene-rich layers, we analyzed the texture in more detail for sample PT-1024 deformed to $\gamma=10.9$, as summarized in Figure 9. In the olivine-rich layer, the olivine grains are still relatively large and tend to be elongated. These grains have the [100] axes oriented approximately parallel to the $X$ direction (blue grains in Figure 9a); the CPO patterns are similar for the olivine-rich layer and the bulk sample (Figures $9 \mathrm{c}$ and 8). The pyroxene grains in the olivine-rich layer are small and approximately equant. The $J$ index is low indicating an approximately uniform distribution (Figure 9d). In the pyroxene-rich layer, the pyroxene grains with a maximum of the [010] axes parallel to the $Y$ direction form a trail approximately parallel to the layering (green grains in Figure 9b). The olivine grains in pyroxene-rich layers are small and equant with a weak fabric indicating an approximately uniform distribution (Figure 9e).

\section{Discussion}

\subsection{Microstructural Changes}

The progression of microstructural changes observed in this study from a larger grained, two-phase mixture to a thoroughly mixed, finergrained texture, as observed in Figures 1-9, is intimately linked to the observed changes in the rate controlling deformation mechanism. The mechanical data presented in our companion paper indicate that the samples deformed by disGBS creep with subgrain boundaries at lower strain $(1 \leq \gamma \leq 3)$ and by disGBS creep without subgrain boundaries at higher strain $(\gamma \geq 24)$. 


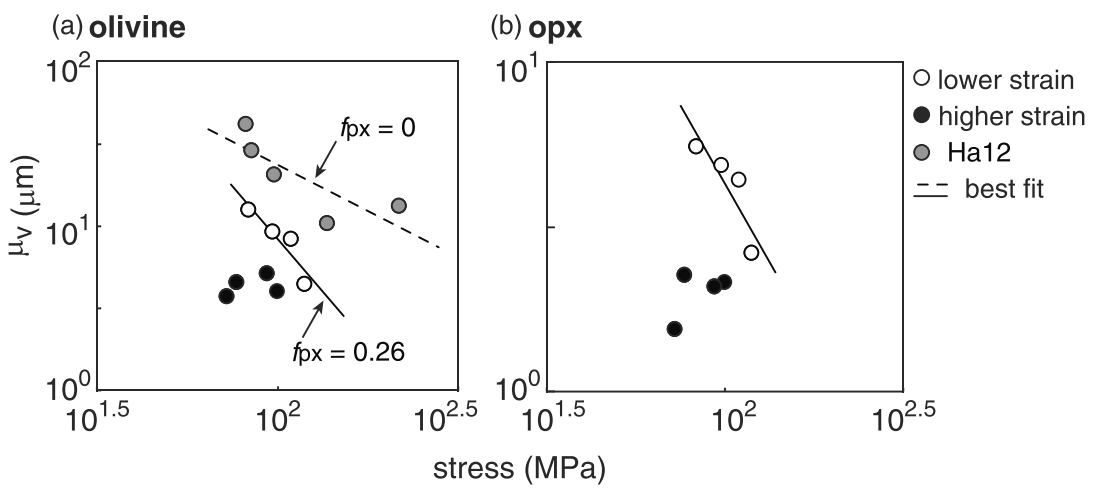

Figure 5. The arithmetic means of histograms of the volume-weighted size distribution, $\mu_{v}$, versus equivalent stress for (a) olivine and (b) pyroxene. Open circle symbols indicate grain sizes from samples deformed to lower strains $(1.9 \leq \gamma \leq 4.2)$. Closed symbols correspond to grain sizes from samples deformed to higher strains (10.9 $\leq \gamma \leq 26.2)$. Gray circle symbols denote steady state-grain sizes for Fo ${ }_{50}$ aggregates with $f_{\mathrm{px}}=0(6.8 \leq \gamma \leq 14.2)$ (Hansen et al., 2012, Ha12). The solid line is the best fit to the grain size-stress data obtained in this study from samples deformed to lower strains $(1.9 \leq \gamma \leq 4.2)$. The dashed line is the best fit for data from Hansen et al. (2012).

Previous theoretical analyses by Langdon $(1994,2006)$ predict a stress exponent of $n=3$ and a grain size exponent of $p=1$ for disGBS creep with subgrain boundaries and $n=2$ and $p=2$ for disGBS creep without subgrain boundaries. Both creep mechanisms are associated with dislocation-accommodated creep; however, disGBS with subgrain boundaries involves dislocation climb into subgrain boundaries and disGBS without subgrain boundaries involves dislocation climb in grain boundaries. Further, based on microstructural observations of samples deformed with strain markers, Langdon (2006) suggested that most of the strain (45 to $70 \%$ or more) is accommodated by grain boundary sliding during disGBS creep with subgrains absent.

To quantify the progression of microstructural changes linked to the deformation mechanism, the crystallographic fabric, piezometric relationship, Zener relationship, and the relative frequency of phase boundaries are examined in following sections.

\subsubsection{Development of Crystallographic Fabric}

The changes in olivine $\mathrm{CPO}$ as a function of strain observed in Figure 8 are associated with changes in the deformation mechanism. In samples deformed to lower strains, $\gamma \approx 2.0$, concentrations of (0kl)[100] orientations of olivine are observed. Samples deformed to somewhat higher strains, $\gamma=4.2$, exhibit a stronger CPO for olivine that is characteristic of slip on the (010)[100] system. Hansen et al. (2014) observed similar CPO patterns and strength changes associated with strain in olivine aggregates without pyroxene $\left(f_{\mathrm{px}}=0\right)$ deformed in the disGBS creep regime with subgrain boundaries. If a strong CPO fabric indicates that the sample deformed by dislocation-accommodated creep with intracrystalline slip and lattice rotation due to dislocation glide, the observed microstructural features indicate that the samples deformed mostly by a

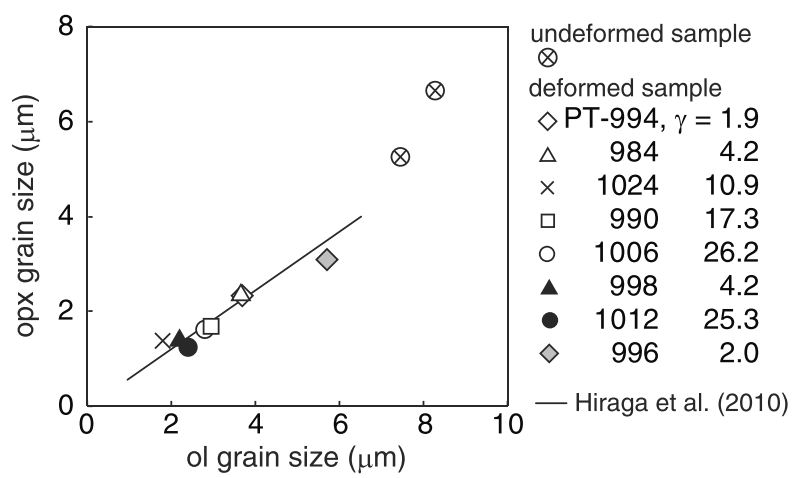

Figure 6. (a) Olivine grain size versus pyroxene grain size. Black line is the estimated grain size derived from the Zener relationship reported in Hiraga et al. (2010) with $z=0.59, \beta=0.74$, and $f_{\mathrm{px}}=0.26$. Open symbols denote samples deformed at a strain rate of $2 \times 10^{-4} \mathrm{~s}^{-1}$, black symbols $5 \times 10^{-4} \mathrm{~s}^{-1}$, and gray symbols $3 \times 10^{-5} s^{-1}$. dislocation-accommodated process with intracrystalline slip, consistent with the deformation mechanism reported in our companion paper.

The more detailed EBSD maps in Figure 9 with a grid spacing of $60 \mathrm{~nm}$ for the sample deformed to $\gamma=10.9$ demonstrate that the primary phase, in this case olivine in olivine-rich layers and pyroxene in pyroxene-rich layers, mostly deformed by a dislocationaccommodated process with intracrystalline slip. In the olivine-rich layers, elongated olivine grains exhibit a well-developed [100] maximum approximately parallel to the shear direction (Figure 9a). These microstructures are often observed in samples deformed by a dislocation-accommodated process in nature and experiment (e.g., Hansen et al., 2012; Linckens et al., 2011). In the pyroxene-rich layers, the pyroxene grains form a weak texture with [010] approximately parallel to the $Y$ direction (Figure 9b), an orientation typical of slip on the (100)[001] slip system in a sample deformed by dislocation creep, as observed in naturally and experimentally deformed 
(a)

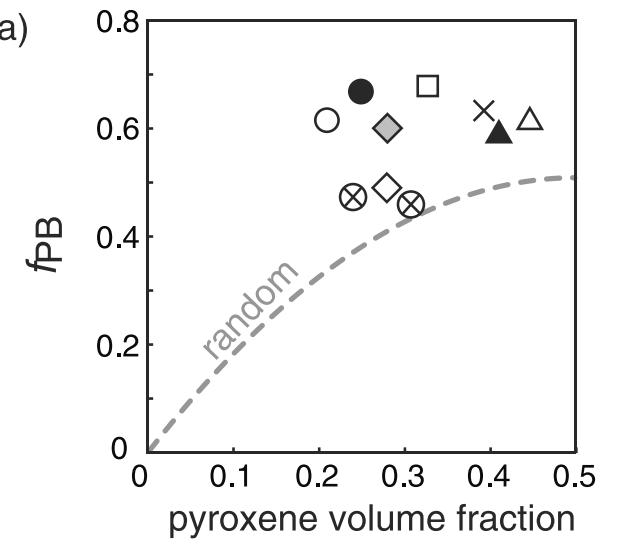

(b)

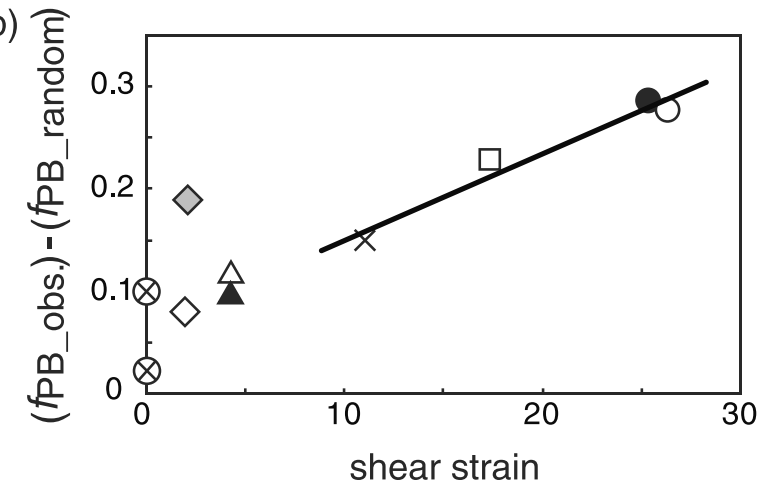

Figure 7. Relative frequency of phase boundaries for varying percentages of pyroxene. (a) Observed frequency of phase boundary length in undeformed and deformed samples ( $f_{\mathrm{PB} \_o b s}$ ) versus pyroxene volume fraction. The gray dashed line indicated the frequency expected for a random spatial distribution $\left(f_{\mathrm{PB}}\right.$ random $)$; values above the line indicate ordering, while values below the line indicate clustering (Heilbronner \& Barrett, 2014). (b) Difference between $f_{\mathrm{PB} \_o b s}$ and $f_{\mathrm{PB} \_ \text {random }}$ versus shear strain. The symbols are the same as in Figure 6. The solid line is a linear fit for samples deformed to $\gamma>10$. orthopyroxene (e.g., Bystricky et al., 2016; Christensen \& Lundquist, 1982; Raterron et al., 2016; Skemer et al., 2006). In contrast, as secondary phases (pyroxene in olivine-rich aggregates and olivine in pyroxene-rich aggregates), both phases show weak textures typical of uniform distributions (Figures $9 d$ and 9e). Furthermore, the grains of the secondary phase are small and equant, without any obvious shape preferred orientation, flowing in the matrix of the primary phase (Figures $9 \mathrm{a}$ and $9 \mathrm{~b}$ ). The lack of CPO in the small and equant grains likely indicates that they have undergone insufficient strain by dislocation glide to develop a clear CPO.

Although the olivine CPO is significantly weaker in samples deformed to higher strains, $\gamma \gtrsim 17$, than in samples deformed to lower strains, $\gamma \approx 4$ (Figures 8 and S3), the CPOs are consistent with slip on the (010)[100] system in both cases. The relatively weak CPO in our most highly strained samples appears to be characteristic of samples deformed in the disGBS without subgrain boundaries creep regime. As Langdon (2006) noted, most of the strain is accommodated by grain boundary sliding in this regime such that intracrystalline slip contributes less and grain boundary sliding contributes more to the total strain than in sample deformed to lower strains. This conclusion is consistent with the lack of dependence of $J$ index on grain size for $d_{\mathrm{ol}}<5 \mu \mathrm{m}$ and the increase in $J$ index for larger grain sizes as reported in Figure S3 for samples deformed to the highest strains. In addition, based on flow law parameters determined in our companion paper for disGBS with and without subgrain boundaries, at $\sigma=76 \mathrm{MPa}$ and an average grain size $=5 \mu \mathrm{m}, 65 \%$ of the strain in sample PT-1006 is due to disGBS with subgrains. Therefore, it is reasonable to anticipate an increase in the value of the $J$ index for larger grain sizes in Figure S3. It should be noted that in all of our experiments, the shear stress exceeds that required to generate dislocations from a Frank-Read source; thus, dislocations are expected to contribute to deformation. To summarize, fabric pattern and strength change with increasing strain (Figures 8, 9, S1, and S3), and the location and number of subgrain boundaries (Figure S2) are consistent with the deformation mechanisms reported in our companion paper.

\subsubsection{Grain Size Controlled by Differential Stress}

With sufficient strain to allow dynamic recrystallization to reach steady-state, the recrystallized grain size is a function of stress for the samples deformed by a dislocation-accommodated creep process (section 2.1). As shown in Figure 5, the average size of both olivine and pyroxene grains decreases with increasing stress in samples deformed to strains of $\gamma \lesssim 4.2$, as predicted by equation (R1). In contrast, the size of olivine and pyroxene grains is nearly constant regardless of stress, strain rate, or strain in samples deformed to strains of $\gamma \gtrsim 11$ (Figure 5). The absence of a grain size dependence on stress indicates that the size of these grains is determined by another process, as described in section 5.2.

Interestingly, the size of olivine grains as a function of stress in our samples with $f_{\mathrm{px}}=0.26$ is smaller than that in the samples with $f_{\mathrm{px}}=0$ (Figure 5a). This difference can be attributed to inhibited grain growth in the two-phase case. The very broad distribution of olivine in the volume-weighted grain size histogram for the samples deformed to lower strains (PT-994 and 984 in Figure 3) is consistent with this assumption. The broad distribution in the size of olivine grains is possibly hiding a second mode at the larger end of the size spectrum. In this case, some olivine grains dynamically recrystallize and grow to a size corresponding to that expressed in equation (R1), whereas the other olivine grains are not able to grow due to the pinning by pyroxene grains (sections 2.2 and 5.13). Therefore, the average grain size is below that predicted by the piezometer for the single-phase material.

\subsubsection{Grain Size Controlled by Zener Relationship}

The grain size ratio for olivine and pyroxene grains is a function of the volume fraction of pyroxene when the polymineralic aggregates are statically annealed and/or deformed by diffusion creep, as described in 


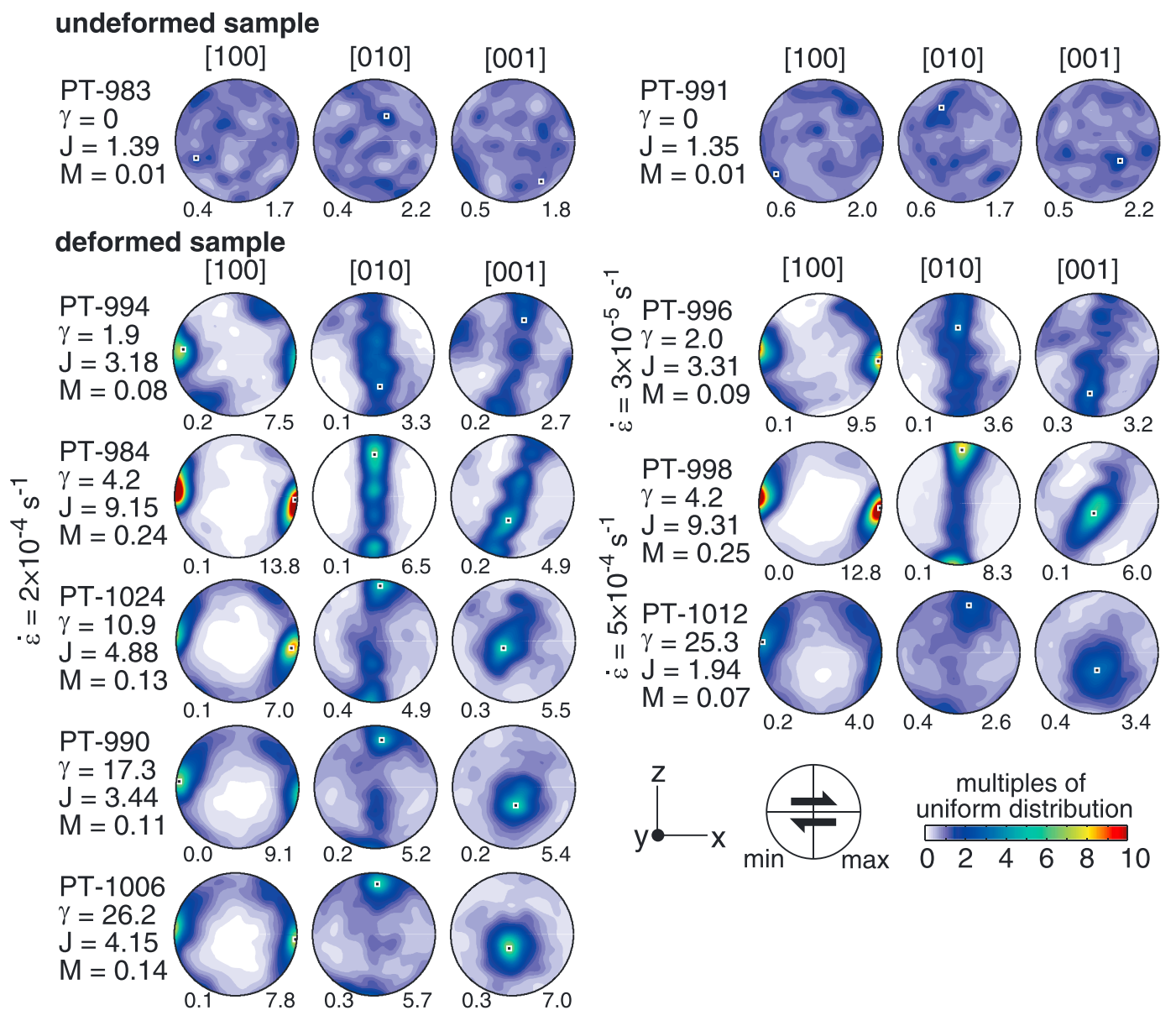

Figure 8. Equal-area pole figures, lower hemisphere projections for olivine [100], [010], and [001] axes for an undeformed and all of the deformed samples. Contours are multiples of uniform distribution. The pole figure densities are weighted by grain area. The values of $J$ and $M$ are the fabric intensities calculated after Mainprice et al. (2000) and Skemer et al. (2005). The data were obtained with a SEM-EBSD system (JEOL 6500F) with the HKL Channel5 software package. The function "texture index (odf)" employing Gaussian filters with half-widths of $5^{\circ}$ in MTEX was used to calculate the values of the $J$ index.

section 2.2. As shown in Figure 6, the Zener relationship holds for all deformed samples, indicating that the pyroxene grains effectively pinned the grain boundaries of olivine, decreasing the rate of grain growth.

The Zener relationship determined from grain growth experiments in Hiraga et al. (2010) at $T=1360^{\circ} \mathrm{C}$, $P=0.1 \mathrm{MPa}$ for polycrystalline aggregates of iron-free forsterite plus enstatite successfully predicts the grain sizes of our deformed samples of iron-rich olivine plus pyroxene (Figure 6). This correlation indicates that the same Zener parameters are applicable regardless of stress, strain, time, temperature, pressure, and iron content of olivine and pyroxene.

\subsubsection{Degree of Phase Mixing Quantified by Boundary Frequency}

The degree of phase mixing can be quantified in terms of the frequency of phase boundaries in the samples. As demonstrated in Figure $7 \mathrm{a}$, all values of $f_{\mathrm{PB} \_ \text {obs }}$ plot in the field above the random curve. As shown in Figure $7 \mathrm{~b}$, the difference between $f_{\mathrm{PB} \_o b s}$ for deformed samples and $f_{\mathrm{PB} \text { random }}$ increases with increasing strain for $\gamma \gtrsim 11$. This behavior indicates that new grains preferentially nucleate on grain boundaries of the opposite phase (as opposed to phase boundaries); that is, new olivine grains nucleate on pyroxene-pyroxene boundaries and new pyroxene grains nucleate on olivine-olivine boundaries. These new grains are smaller $\left(d_{\mathrm{ol}}\right.$ and $\left.d_{\mathrm{px}} \approx 1 \mu \mathrm{m}\right)$ than the dynamically recrystallized grains and equant (Figures $2 \mathrm{~b}$ and $2 \mathrm{c}$ ). Further, the small pyroxene grains form trails along olivine grain boundaries, and the small olivine grains occur along pyroxene grain boundaries in samples deformed to lower strain. Since these small, equant grains of olivine and pyroxene are absent in the undeformed sample, they must have formed during deformation. 

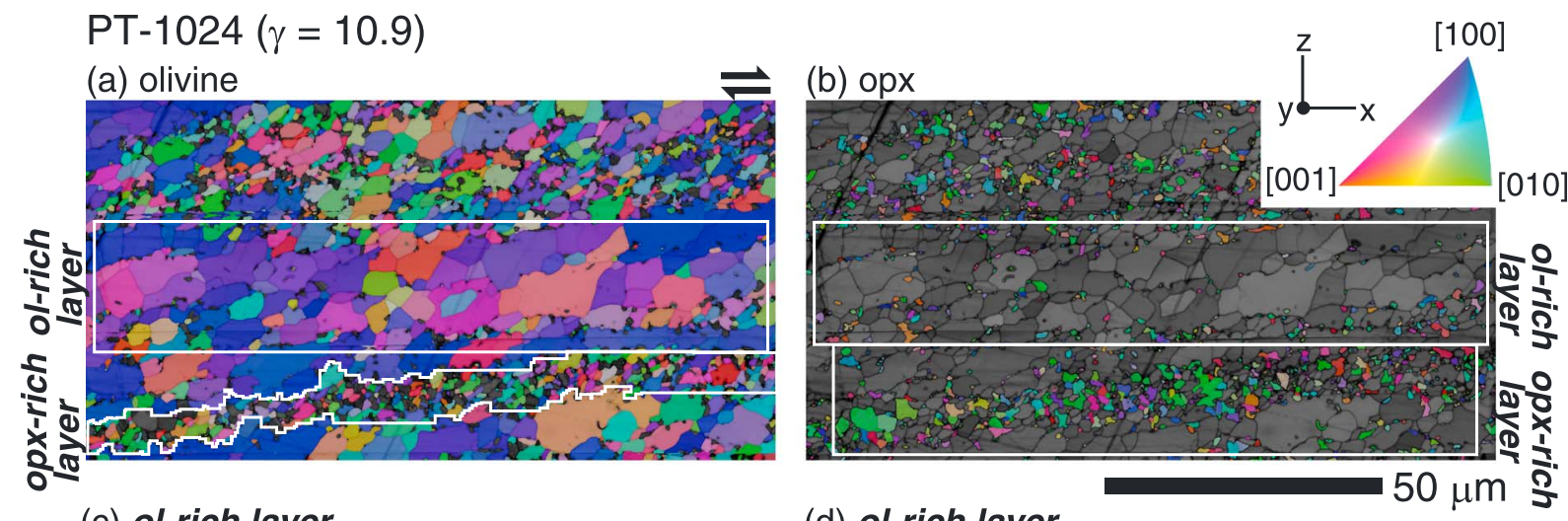

(c) ol-rich layer

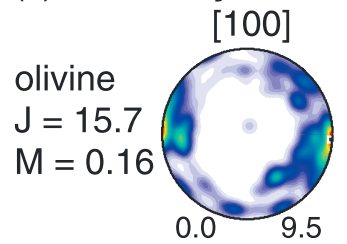

(e) opx-rich layer

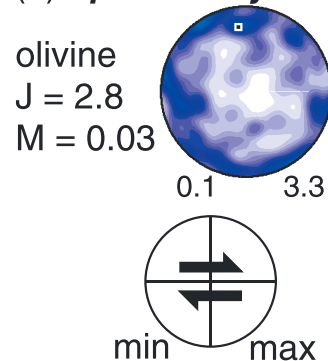

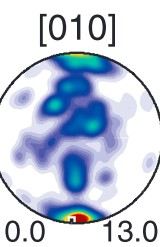
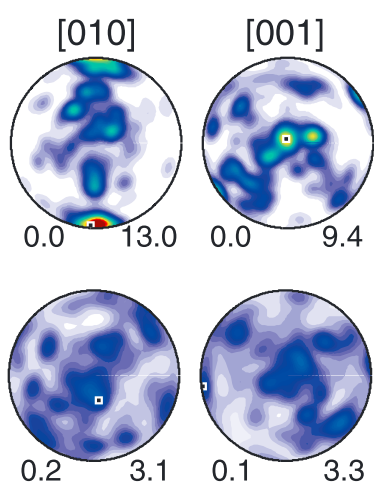

multiples of uniform distribution

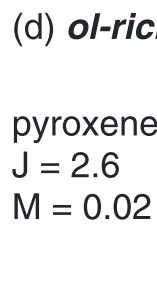

(f) opx-rich layer

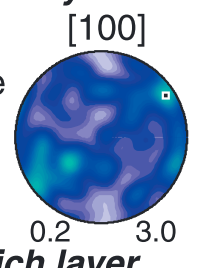

pyroxene

$\mathrm{J}=3.2$

$M=0.04$
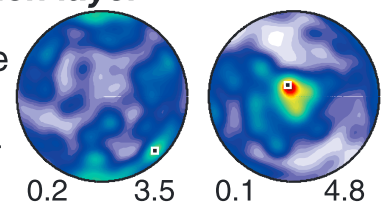

multiples of uniform distribution

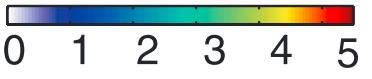

Figure 9. Orientation maps from EBSD analyses of (a) olivine and (b) pyroxene using inverse pole figure (IPF) coloring of the $X$ direction for olivine and of the $Y$ direction for pyroxene; see lookup table in upper right. Area-weighted pole figures in Figures $9 \mathrm{c}$ and $9 \mathrm{e}$ for olivine and in Figures $9 \mathrm{~d}$ and $9 \mathrm{f}$ for pyroxene are derived from the areas shown in white boxes in the EBSD maps in Figures $8 \mathrm{a}$ and $8 \mathrm{~b}$. The $J$ and $M$ indices are indicated. The data were obtained with a field emission SEM (Zeiss Merlin Compact FE-SEM) employing the AZtecHKL software package.

\subsection{Formation of Well-Mixed, Fine-Grained Aggregates}

The major elements in both olivine and orthopyroxene are $\mathrm{Me}, \mathrm{O}$, and $\mathrm{Si}$, where $\mathrm{Me}=\mathrm{Fe}$ or $\mathrm{Mg}$. Furthermore, $\mathrm{Si}$ is the slowest diffusing species for iron-free and iron-bearing olivine and orthopyroxene, both through the crystal lattice and along the grain boundaries (e.g., for olivine: Farver \& Yund, 2000 \& Dohmen et al., 2002 and for pyroxene: Milke et al., 2007; Gardes et al., 2011; Gardes \& Heinrich, 2011). The microstructural development observed in Figures 1 and 2 can be explained by the difference in diffusivities of Me, O, and $\mathrm{Si}$, with the transport of $\mathrm{MeO}$ being substantially faster than that of $\mathrm{SiO}_{2}$.

As illustrated in Figure 10, stress-directed diffusion occurs in response to an imposed nonhydrostatic stress. All three of the constituent ions diffuse from regions of maximum deviatoric compression, $\sigma_{1}$, to regions of deviatoric tension, $\sigma_{3}$. However, since $\mathrm{MeO}$ is significantly more mobile than $\mathrm{SiO}_{2}, \mathrm{MeO}$ relatively quickly diffuses out of olivine-olivine grain boundaries experiencing maximum deviatoric compressive stress leaving behind new pyroxene grains via the reaction $\mathrm{Me}_{2} \mathrm{SiO}_{4}-\mathrm{MeO} \rightarrow \mathrm{MeSiO}_{3}$, as depicted in Figure 10a and discussed in detail by Sundberg and Cooper (2008). The more mobile component, $\mathrm{MeO}$, then diffuses to a grain-grain interface under deviatoric tension. If that interface is a pyroxenepyroxene grain boundary, an olivine grain can form by the reaction $\mathrm{MeSiO}_{3}+\mathrm{MeO} \rightarrow \mathrm{Me}_{2} \mathrm{SiO}_{4}$ (Figure 10a). Again, this process is only possible because both olivine and enstatite are composed of $\mathrm{MeO}+\mathrm{SiO}_{2}$ components and $D_{\mathrm{Me}}, D_{\mathrm{O}}>D_{\mathrm{Si}}$.

Our hypothesis for explaining the phase-mixing process in the olivine-orthopyroxene system is consistent with the observed microstructure, as described below. 
(a) phase mixing due to $\mathrm{MeO}$ transport
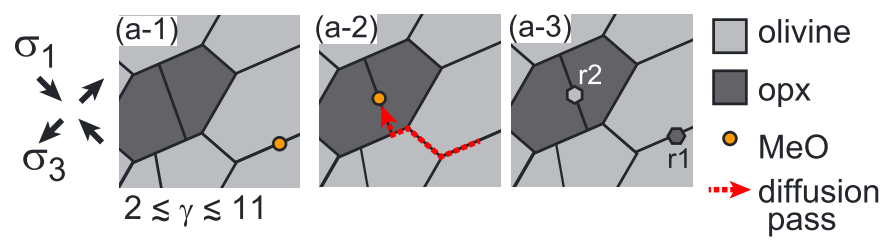

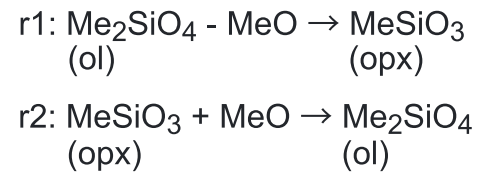

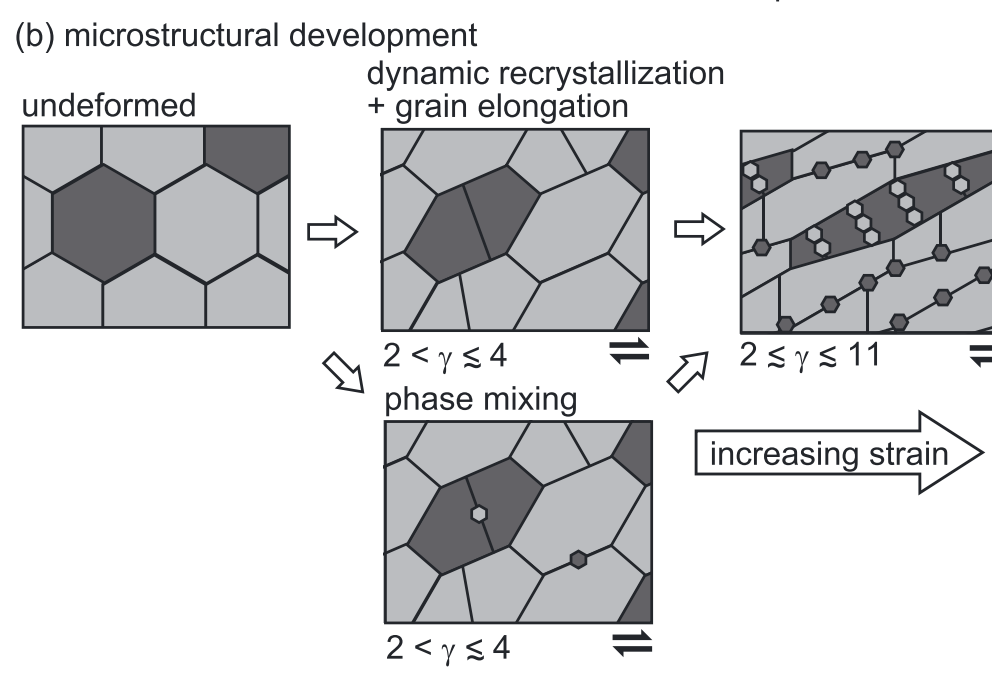

Figure 10. Schematic diagrams illustrating the process of grain-size reduction and phase mixing by dynamic recrystallization and heterogeneous nucleation. (a) Driven by the imposed stress potential gradient, all three of the constituent ions diffuse from regions of maximum deviatoric compression, $\sigma_{1}$, to regions of deviatoric tension, $\sigma_{3}$. (a1) $\mathrm{MeO}$ in olivine dissolves into grain boundaries experiencing maximum compressive deviatoric stress, $\sigma_{1}$, and (a2) the more mobile component, $\mathrm{MeO}$, then diffuses to a grain-grain interface under deviatoric tension, $\sigma_{3}$. (a3) Due to the missing and transported MeO, reaction 1 (R1) and reaction 2 (R2) occur. Light gray and dark gray grains are olivine and pyroxene, respectively. Orange circle is MeO. Red arrow is transport path of MeO. (b) Microstructural development observed in this study. White arrows indicate increasing strain.

1. In olivine-rich layers (Figure 2b), small pyroxene grains are located along olivine grain boundaries that are approximately perpendicular to $\sigma_{1}$. In pyroxene-rich layers (Figure 2c), small olivine grains are located on pyroxene grain boundaries approximately normal to $\sigma_{3}$. These microstructures are observed in all of our samples deformed to shear strains of $1.9 \leq \gamma \leq 4.2$.

2. The frequency of phase boundaries increases with increasing strain, Figure $7 \mathrm{~b}$, indicating that new grains preferentially form on grain boundaries of the opposite phase.

3. The size of both the olivine and the pyroxene grains in samples deformed to high strains $(\gamma \gtrsim 11)$ is significantly smaller than predicted by the piezometers determined on single-phase samples (Figure 5), indicating that the grain sizes in the two-phase samples are not simply related to dynamic recrystallization but must involve phase mixing and Zener pinning. Note that the ratio of the olivine-to-pyroxene grain size is well described by the Zener relationship with values for the Zener parameters determined by Hiraga et al. (2010).

4. Further, the absence of a pronounced CPO of the isolated, small equant grains of the secondary phase (Figures $9 \mathrm{~d}$ and $9 \mathrm{e}$ ) indicates that these grains do not form due to dynamic recrystallization but require another process such as the nucleation process described in Figure 10.

\subsection{Diffusion Creep or Dislocation-Accommodated Grain Boundary Sliding?}

It is often argued that the grain size reduction associated with phase mixing and Zener pinning causes a transition from a dislocation-dominated creep mechanism to diffusion creep (Bercovici \& Skemer, 2017; Hansen \& Warren, 2015; Herwegh et al., 2011; Linckens et al., 2011, 2015; Warren \& Hirth, 2006). Two results from the present study - one based on deformation results and the other on microstructural observationsindicate that this transition does not occur in our experiments. Here we assert that the weakening observed with increasing strain in our experiments is due to a transition from disGBS with subgrains to disGBS without subgrains. 
First, the experimentally determined values for the stress and grain size exponents $(n, p)$ provide information on the dominant deformation mechanism. Values for $(n, p)$ of $(1,2)$ and $(1,3)$ are predicted from models of diffusion creep in which diffusion is through the lattice (Herring, 1950; Nabarro, 1948) and along grain boundaries (Coble, 1963), respectively. The values of $(n, p) \approx(2,3)$ reported in our companion paper are not consistent with those predicted by either of the diffusion creep models, noting specifically that both yield stress exponents of $n=1$. It should be noted that values for $(n, p)$ of $(2,1)$ are anticipated for interface-controlled diffusion creep (Arzt et al., 1983). These values were, in fact, observed for olivine-orthopyroxene samples (Sundberg \& Cooper, 2008); however, the associated CPO exhibited alignment of [001] axes in the shear direction, in contrast alignment of [100] axes in the shear direction in our experiments (see also the Discussion in our companion paper, Tasaka et al., 2017). Thus, we conclude that our values of $(n, p) \approx(2,3)$ determined in our highest strain experiments are consistent within experimental uncertainty with those predicted for disGBS without subgrain boundaries of $(n, p)=(2,2)$ and do not signal a transition to diffusion creep.

Second, the SPO developed during our torsion experiments (Figure 4) indicate that deformation was dominated by a dislocation mechanism. In diffusion creep experiments, elongated grains passively rotate into the shear direction with increasing strain (Miyazaki et al., 2013). In this case, the SPO should be nearly equal to the imposed shear direction for a shear strain of $\gamma=26.2$. As illustrated in Figure 4, however, the long axes of grains in our sample that was sheared to this extent align at $\sim 30^{\circ}$ to the shear direction. This difference between shear direction and the SPO is typical of samples deformed by dislocation glide and climb combined with dynamic recrystallization (Herwegh \& Handy, 1996; Zhang \& Karato, 1995). Thus, both the mechanical response and the microstructural evolution of our highly deformed, two-phase samples indicate that strain dominantly occurred by a dislocation-mediated mechanism.

\subsection{Observed Grain Size Reduction, Rheological Weakening, and Geological Implications}

Based on the microstructural observation discussed above, we conclude that two independent grain size reduction mechanisms operate in parallel during our deformation experiments. (i) At lower strains $(\gamma \leq 4.2)$, dislocation-accommodated creep with intracrystalline dislocation slip and lattice rotation contribute significantly to the bulk deformation, forming dynamically recrystallized grains following the grain size piezometer (Figure 5). (ii) At higher strains $(\gamma \geq 17.3)$, intracrystalline slip contributes less to the bulk strain; instead, relatively small olivine and pyroxene grains nucleate along grain boundaries of the opposite phase, leading to a more thoroughly mixed, fine-grained aggregate of olivine and pyroxene. The former grain size reduction mechanism is observed in low strain samples with pyroxene $\left(f_{\mathrm{px}}=0.26\right)$ and without $\left(f_{\mathrm{px}}=0\right.$, see also Hansen et al., 2012), whereas the latter grain size reduction mechanism is only effective in pyroxenebearing samples.

The microstructural development observed in this study is summarized in Figure 10b. At lower strains of $\gamma \lesssim 4$, both olivine and pyroxene grains deform by disGBS creep with subgrain boundaries. At these strains, both olivine and pyroxene grains progressively elongate $(\gamma \leq 4.2$ in Figures 1 and 2$)$ and during this process dynamically recrystallize (Figure 5 ). At intermediate strains $(2 \lesssim \gamma \lesssim 11)$, small, new grains of olivine and pyroxene begin to form, effectively pinning the grain boundaries of the opposite phase following the Zener relationship (Figure 6). As a result, the average grain size decreases with increasing strain (Figures 1 and 3 and Table 1). The process of nucleation and growth of small grains along the grain boundaries of the opposite phase produces more phase boundaries (Figure 7), resulting in intensive phase mixing. Dynamic recrystallization is no longer active in samples deformed to higher strain due to the reduced grain size (Figure 5). Eventually, most grains are replaced by newly nucleated grains, producing a fine-grained aggregate $(\gamma=25.3$ and 26.2 in Figure 1). Reduction in grain size and increase in the concentration of phase boundaries due to the grain formation process described in section 5.2 lead to a change in deformation mechanism described by a strain rate dependence on stress with a lower exponent and on grain size with a higher exponent, producing strain weakening during grain size sensitive creep.

Microstructures and deformation mechanisms similar to those in our samples deformed to low and high strain (Figures 1 and 2) are observed in naturally deformed harzburgite mylonites and ultramylonites. For example, Czertowicz et al. (2016) described small, isolated pyroxene grains located on olivine-olivine grain boundaries and at olivine triple junctions. Based on field and microstructural observations, these authors suggested that due to phase mixing, strain localization occurred in the center portion of the shear zone. Linckens et al. (2011) and Michibayashi and Mainprice (2004) reported that olivine microstructures from 
coarse-grained porphyroclastic to fine-grained ultramylonite textures develop toward the center of shear zones. The ultramylonite consisted of more thoroughly mixed, fine-grained ( $10 \mu \mathrm{m})$ aggregations of olivine and pyroxene with a relatively weak olivine CPO. Based on microstructural analyses, these researchers concluded that strain weakening occurred in the central portion of the shear zone associated with deformation by a grain size sensitive creep mechanism. Kilian et al. (2011) described similar microstructures for a metagranodiorite with a quartz content of $\sim 30 \%$ plus K-feldspar, biotite, plagioclase, and white mica.

The consistency between microstructures observed in our experimental study and those observed in naturally deformed rocks indicates that the rheological and microstructural evolution quantified in our study provides a good basis for understanding natural shear zones. Consequently, the process of phase mixing during deformation as proposed in this study (section 5.2) and the resulting changes in rheological behavior reported in our companion paper provide a framework for understanding rheological weakening associated with localization in natural shear zones.

\section{Acknowledgments}

We thank A. Dillman, J. Tielke, M. Pec C. Qi, C. Meyers, and Z. Michels for helpful discussions and technical assistance, T. Hiraga and M. Morishige for valuable discussions, A. van der Handt for assistance of electron microprobe analyses, and B. Richter and N. Seaton for assistance of EBSD analysis. We thank L. Hansen for providing the original EBSD data in Hansen et al. (2012). The manuscript was significantly improved by insightful comments from two reviewers, R. Cooper and L. Hansen, and an Editor, M. Walter. This study was supported by a JSPS Research Fellowship for Young Scientists (26-4879) and the Japan Society for the Promotion of Science (16K17832) to M. T., a NASA grant (NNX15AL53G) to D. L. K., and a NSF grant (EAR-1345060) and a NASA grant (NNX11AF58G) to M. E. Z. Parts of this work were carried out in the Characterization Facility, University of Minnesota, which is a member of the NSF-funded Materials Research Facilities Network (www.mrfn. org) via the MRSEC program. Electron microprobe analyses were carried out at the Electron Microprobe Laboratory, Department of Earth Sciences, University of Minnesota, Twin Cities, and some of the EBSD work at the Department of Geosciences of the University of Tromso, Norway. Data used in this paper are available in the main text and supporting information.

\section{References}

Arzt, E., Ashby, M. F., \& Verrall, R. A. (1983). Interface controlled diffusional creep. Acta Metallurgica, 31, 1977-1989. Bercovici, D., \& Ricard, Y. (2014). Plate tectonics, damage and inheritance. Nature, 508, 513-516. https://doi.org/10.1038/nature13072 Bercovici, D., \& Skemer, P. (2017). Grain damage, phase mixing and plate-boundary formation. Journal of Geodynamics, 108, 40-55. https:// doi.org/10.1016/j.jog.2017.05.002

Bercovici, D., Ricard, Y., \& Richards, M. A. (2000). The relation between mantle dynamics and plate tectonics: A primer. In M. Richards, R. Gordon, \& R. van der Hilst (Eds.), The History and Dynamics of Global Plate Motions, Geophysical Monograph Series (Vol. 121, pp. 5-46). Washington, DC: American Geophysical Union.

Bystricky, M., Lawlis, J., Mackwell, S., Heidelbach, F., \& Raterron, P. (2016). High-temperature deformation of enstatite aggregates. Journal of Geophysical Research: Solid Earth, 121, 6384-6400. https://doi.org/10.1002/2016JB013011

Christensen, N. I., \& Lundquist, S. M. (1982). Pyroxene orientation within the upper mantle. Geological Society of America Bulletin, 93, 279-288.

Coble, R. (1963). A model for boundary diffusion controlled creep in ceramic materials. Journal of Applied Physics, 34(6), $1679-1682$.

Czertowicz, T. A., Toy, V. G., \& Scott, J. M. (2016). Recrystallisation, phase mixing and strain localisation in peridotite during rapid extrusion of sub-arc mantle lithosphere. Journal of Structural Geology, 88, 1-19. https://doi.org/10.1016/j.jsg.2016.04.011

Dohmen, R., Chakraborty, S., \& Becker, H. W. (2002). Si and O diffusion in olivine and implications for characterizing plastic flow in the mantle. Geophysical Research Letters, 29(21), 2030. https://doi.org/10.1029/2002GL015480

Evans, B., Renner, J., \& Hirth, G. (2001). A few remarks on the kinetics of static grain growth in rocks. International Journal of Earth Sciences, 90 , 88-103.

Farla, R., Karato, S., \& Cai, Z. (2013). Rule of orthopyroxene in rheological weakening of the lithosphere via dynamic recrystallization. PNAS, 110(41), 16,355-16,360. https://doi.org/10.1073/pnas.1218335110

Farver, J. R., \& Yund, R. A. (2000). Sillicon diffusion in forsterite aggregates: Implications for diffusion accommodated creep. Geophysical Research Letters, 27, 2337-2340.

Gardes, E., \& Heinrich, W. (2011). Growth of multilayered polycrystalline reaction rims in the $\mathrm{MgO}^{-\mathrm{SiO}_{2}}$ system, part II: Modeling. Contributions to Mineralogy and Petrology, 162, 37-49.

Gardes, E., Wunder, B., Wirth, R., \& Heinrich, W. (2011). Growth of multilayered polycrystalline reaction rims in the MgO-SiO2 system, part l: Experiments. Contributions to Mineralogy and Petrology, 161, 1-12.

Handy, M. R., \& Stünitz, H. (2002). Strain localization by fracturing and reaction weakening-A mechanism for initiating exhumation of subcontinental mantle beneath rifted margins. In S. de Meer et al. (Eds.), Deformation Mechanisms, Rheology and Tectonics: Current Status and Future Perspectives Geological Society, London, Special Publications, 200, 321-342, London.

Hansen, L. N., \& Warren, J. M. (2015). Quantifying the effect of pyroxene on deformation of peridotite in a natural shear zone. Journal of Geophysical Research: Solid Earth, 120, 2717-2738. https://doi.org/10.1002/2014JB011584

Hansen, L. N., Zimmerman, M. E., \& Kohlstedt, D. L. (2012). The influence of microstructure on deformation of olivine in the grain-boundary sliding regime. Journal of Geophysical Research, 117, B09201. https://doi.org/10.1029/2012JB009305

Hansen, L. N., Zimmerman, M. E., \& Kohlstedt, D. L. (2014). Protracted fabric evolution in olivine: Implications for the relationship among strain, crystallographic fabric, and seismic anisotropy. Earth and Planetary Science Letters, 387, 157-168. https://doi.org/10.1016/j. epsl.2013.11.009

Heilbronner, R., \& Barrett, S. (2014). Image Analysis in Earth Science: Microstructures and Textures of Earth Materials (pp. 351-368). Heidelberg: Springer.

Herring, C. (1950). Diffusional viscosity of a polycrystalline solid. Journal of Applied Physics, 21(5), 437-445.

Herwegh, M., \& Handy, M. (1996). The evolution of high-temperature mylonitic microfabrics: Evidence from simple shearing of a quartz analogue (norcamphor). Journal of Structural Geology, 18(5), 689-710.

Herwegh, M., Linckens, J., Ebert, A., Berger, A., \& Brodhag, S. H. (2011). The role of second phases for controlling microstructural evolution in polymineralic rocks: A review. Journal of Structural Geology, 33, 1728-1750.

Hiraga, T., Tachibana, C., Ohashi, N., \& Sano, S. (2010). Grain growth systematics for forsterite \pm enstatite aggregates: Effect of lithology on grain size in the upper mantle. Earth and Planetary Science Letters, 291, 10-20.

Hirth, G., \& Kohlstedt, D. L. (2015). The stress dependence of olivine creep rate: Implications for extrapolation of lab data and interpretation of recrystallized grain size. Earth and Planetary Science Letters, 418, 20-26.

Jin, D., Karato, S., \& Obata, M. (1998). Mechanisms of shear localization in the continental lithosphere: Inference from the deformation microstructures of peridotites from the Ivrea zone, northern Italy. Journal of Structural Geology, 20, 195-209.

Kelemen, P. B., \& Dick, H. J. B. (1995). Focused melt flow and localized deformation in the upper mantle: Juxtaposition of replacive dunite and ductile shear zones in the Josephine peridotite. SW Oregon. Journal of Geophysical Research, 100, 423-438.

Kilian, R., Heilbronner, R., \& Stunitz, H. (2011). Quartz grain size reduction in a granitoid rock and the transition from dislocation to diffusion creep. Journal of Structural Geology, 33, 1265-1284. 
Langdon, T. G. (1994). A unified approach to grain boundary sliding in creep and superplasticity. Acta Metallurgica et Materialia, 42(7), 2437-2443.

Langdon, T. G. (2006). Grain boundary sliding revisited: Developments in sliding over four decades. Journal of Materials Science, 41, 597-609. https://doi.org/10.1007/s10853-006-6476-0

Linckens, J., Herwegh, M., Muntener, O., \& Mercolli, I. (2011). Evolution of a polymineralic mantle shear zone and the role of second phases on the localization of deformation. Journal of Geophysical Research, 116, B06210. https://doi.org/10.1029/2010JB008119

Linckens, J., Bruijn, R. H. C., \& Skemer, P. (2014). Dynamic recrstallization and phase mixing in experimentally deformed peridotite. Earth and Planetary Science Letters, 388, 134-142.

Linckens, J., Herwegh, M., \& Muntener, O. (2015). Small quantity but large effect - How minor phases control strain localization in upper mantle shear zones. Tectonophysics, 643, 26-43.

Mainprice, D., Barruol, G., \& Ismaill, W. (2000). The anisotropy of the Earth's mantle: From single crystal to polycrystal. In S. Karato et al. (Eds.) Mineral Physics and Seismic Tomography: From Atomic to Global, AGU Geophysical Monograph (Vol. 117, pp. 237-264). Washington, DC.

Manohar, P. A., Ferry, M., \& Chandra, T. (1998). Five decades of the Zener equation. ISIJ International, 38(9), 913-924.

Michibayashi, K., \& Mainprice, D. (2004). The role of pre-existing mechanical anisotropy on shear zone development within oceanic mantle lithosphere: An example from the Oman ophiolite. Journal of Petrology, 45, 405-414.

Milke, R., Dohmen, R., Becker, H. W., \& Wirth, R. (2007). Growth kinetics of enstatite reaction rims studied on nano-scale, part I: Methodology, microscopic observations and the role of water. Contributions to Mineralogy and Petrology, 154, 519-533.

Miyazaki, T., Sueyoshi, K., \& Hiraga, T. (2013). Olivine crystals align during diffusion creep of Earth's upper mantle. Nature, 502, $321-326$.

Nabarro, F. (1948), Deformation of crystals by the motion of single ions, in Report of a Conference on Strength of Solids (pp. 75-90).

Newman, J., Lamb, W. M., Drury, M. R., \& Vissers, R. L. M. (1999). Deformation processes in a peridotite shear zone: Reaction-softening by an $\mathrm{H}_{2} \mathrm{O}$-deficient continuous net transfer reaction. Tectonophysics, 303, 193-222.

Precigout, J., Pregent, C., Palasse, L., \& Pochon, A. (2017). Water pumping in mantle shear zone. Nature Communications, 8, 15,736. https://doi. org/10.1038/ncomms15736

Raterron, P., Fraysse, G., Girard, J., \& Holyoke, C. W. (2016). Strength of orthoenstatite single crystals at mantle pressure and temperature and pmparison with olivine. Earth and Planetary Science Letters, 450, 326-336.

Skemer, P., Katayama, I., Jiang, Z., \& Karato, S. (2005). The misorientation index: Development of a new method for calculating the strength of lattice-preferred orientation. Tectonophysics, 411, 157-167.

Skemer, P., Katayama, I., \& Karato, S. (2006). Deformation fabrics of the Cima di Gagnone peridotite massif, Central Alps, Switzerland: Evidence of deformation at low temperature in the presence water. Contributions to Mineralogy and Petrology, 152, 43-51.

Smith, C. S. (1948). Grains, phases, interfaces: An interpretation of microstructures. Transactions of the American Institute of Mining and Metallurgical Engineers, 175, 15-51.

Sundberg, M., \& Cooper, R. F. (2008). Crystallographic preferred orientation produced by diffusional creep of harzburgite: Effects of chemical interactions among phases during plastic flow. Journal of Geophysical Research, 113, B12208. https://doi.org/10.1029/2008JB005618

Tackley, P. (2000). The quest for self-consistent generation of plate tectonics in mantle convection models. In M. A. Richards, R. G. Gordon, \& R. D. van der Hilst (Eds.), The History and Dynamics of Global Plate Motions, Geophysical Monograph Series (Vol. 121, pp. 47-72). Washington, DC: American Geophysical Union.

Tasaka, M., \& Hiraga, T. (2013). Influence of mineral fraction on the rheological properties of forsterite + enstatite during grain size sensitive creep: 1. Grain size and grain growth laws. Journal of Geophysical Research: Solid Earth, 118, 1-21. https://doi.org/10.1002/jgrb.50285

Tasaka, M., Hiraga, T., \& Michibayashi, K. (2014). Influence of mineral fraction on the rheological properties of forsterite + enstatite during grain size sensitive creep creep: 3 . Application of grain growth and flow laws on peridotite ultramylonite. Journal of Geophysical Research: Solid Earth, 119, 840-857. https://doi.org/10.1002/2013JB010619

Tasaka, M., Zimmerman, M. E., \& Kohlstedt, D. L. (2015). Creep behavior of Fe-bearing olivine under hydrous conditions. Journal of Geophysical Research: Solid Earth, 120, 6039-6057. https://doi.org/10.1002/2015JB012096

Tasaka, M., Zimmerman, M. E., \& Kohlstedt D. L. (2016). Evolution of the rheological and microstructural properties of olivine aggregates during dislocation creep under hydrous conditions. Journal of Geophysical Research: Solid Earth, 121, 92-113. https://doi.org/10.1002/ 2015JB012134

Tasaka, M., Zimmerman, M. E., \& Kohlstedt, D. L. (2017). Rheological weakening of olivine + orthopyroxene aggregates due to phase mixing: Part 1. Mechanical behavior. Journal Geophysical Research: Solid Earth, 122, https://doi.org/10.1002/2017JB014333

Twiss, R. J. (1977). Theory and applicability of a recrystallized grain size paleopiezometer. Pure and Applied Geophysics, 115(1-2), 227-244. https://doi.org/10.1007/BF01637105

Underwood, E. (1970). Quantitative Stereology. Reading, MA: Addison-Wesley.

von Seckendorff, V., \& O'Neill, H. S. C. (1993). An experimental study of Fe-mg partitioning between olivine and orthopyroxene at 1173,1273, and $1423 \mathrm{~K}$ and $1.6 \mathrm{GPa}$. Contributions to Mineralogy and Petrology, 113, 196-207. https://doi.org/10.1007/BF00283228

Warren, J. M., \& Hirth, G. (2006). Grain size sensitive deformation mechanisms in naturally deformed peridotites. Earth and Planetary Science Letters, 248(1-2), 438-450. https://doi.org/10.1016/j.epsl.2006.06.006

Zhang, S., \& Karato, S. (1995). Lattice preferred orientation of olivine aggregates deformed in simple shear. Nature, 375, $774-777$.

Zhao, Y., Zimmerman, M. E., \& Kohlstedt, D. L. (2009). Effect of iron content on the creep behavior of olivine: 1. Anhydrous conditions. Earth and Planetary Science Letters, 287, 229-240. https://doi.org/10.1016/j.epsl.2009.08.006 